\title{
A Basis of the Stomatocytoses of Erythrocytes by 1-Chloro-2, 4- Dinitrobenzene and Other Electrophilic Reagents
}

\author{
Pierre Wong*
}

LCP, Section Théorique, Canada

\begin{abstract}
On bases of previous observations on the band 3 anion exchange inhibition by the electrophilic reagent 1-fluoro-2,4-dinitrobenzene in resealed ghosts and a previously proposed band 3-based mechanism of control of the erythrocyte shape, it is suggested that stomatocytoses by 1-chloro-2,4-dinitrobenzene and other electrophilic reagents are due to an inhibition of the band 3 anion exchange by a covalent modification of Lys 539, one of the two lysine intramolecularly cross-linked by impermeant 4,4'-diisothiocyanodihydrostilbene-2,2'- disulfonic acid, a band 3 anion exchange potent inhibitor. Attempts to explain these stomatocytoses led to explain the echinocytosis and competitive inhibition of band 3 anion exchange by stilbenedisulfonic acid derivatives and the reversal of the echinocytosis by 2,4dinitrophenol by one stomatocytogenic of the electrophilic reagents. The inference on stomatocytoses by electrophilic reagents is of interest since stomatocytogenic and echinocytogenic by amphiphiles are perceived to interact noncovalently with the membrane and that they can be clinically relevant.
\end{abstract}

Keywords: Band 3, echinocytosis, 1-fluoro-2,4-dinitrobenzene, glucose, stilbenedisulfonic acid, stomatocytosis, skeleton.

The electrophilic reagent 1-chloro-2,4-dinitrobenzene (CDNB) at a relative low concentration $(0.5-2 \mathrm{mM})$ in an isotonic buffered saline depletes the erythrocyte glutathione within a period of $60 \mathrm{~min}$ at $37^{\circ} \mathrm{C}$ by a dinitrophenylation of its cysteine residue by the intermediary of glutathione $\mathrm{S}$ transferase [1-3]. This depletion is accompanied by a $\mathrm{K}^{+}$ leakage, a stomatocytosis and a decrease of the erythrocyte deformability [2], and a negligible hemolysis [3] becoming prominent at a higher CDNB concentration $(5 \mathrm{mM})[2,4]$. This stomatocytosis was noticed during a survey of a literature in order to test the validity of a previously proposed band 3-based mechanism of control of the erythrocyte shape [5]. It appeared to be due to dinitrophenylations of membrane proteins and aminophospholipids since it was observed after cell washing [2]. However, it appeared unrelated to dinitrophenylations of cysteine residues of membrane proteins since alkylations of these cysteine residues by N-ethylmaleimide $(5-9.5 \mathrm{mM})$ or iodoacetamide $(9.5 \mathrm{mM})$ opposed to echinocytosis by salicylate [6] and to stomatocytosis by chlorpromazine or Triton-X-100 [6, 7], apparently by reducing the skeleton flexibility. The band 3-based mechanism did not appear to be able to explain this stomatocytosis as well as other echinocytoses and stomatocytoses by other agents, including the echinocytosis by glucose depletion. However, recently, a process of echinocytosis by glucose depletion has been proposed based on this mechanism [5] and the following previous observations on ghosts and erythrocytes with other electrophilic reagents have drawn our attention, which led us

\footnotetext{
* Address correspondence to this author at the Laboratoire de Chimie des Protéines, Section Théorique, 3415 Aylmer, Montréal, Québec, Canada H2X 2B4; Tel: 514-849-1550; E-mail: pwong_LCP@yahoo.ca
}

to a second attempt to explain the stomatocytosis by CDNB by this mechanism. The structural analogue 1-fluoro-2,4dinitrobenzene (FDNB) inhibited the band 3 anion exchange in resealed ghosts at a relatively low concentration (0.15-0.3 $\mathrm{mM}$ ) [7-10]. The affinity labels of proteases N- $\alpha$-tosyl-Lphenylalanine-chloromethyl ketone (TPCK) and N- $\alpha$-tosylL-lysine-chloromethyl ketone (TLCK) and one of the impurities of the insecticide bromfenvinphos, 2,4dichlorophenacyl bromide, induced stomatocytoses under similar conditions with the exception of a higher TLCK concentration required $(4 \mathrm{mM})$ to induce it, presumably being due to be more polar [11-14]. These observations suggested that stomatocytoses by CDNB and other electrophilic reagents have a common basis and result from a covalent modification of band 3. Attempts to explain these stomatocytoses also led to explain observations related to stilbenedisulfonic acid derivatives, which are potent inhibitors of the band 3 anion exchange, a reversal of an echinocytosis by the amphiphile 2,4-dinitrophenol (DNP) amphiphile by the electrophilic reagent TPCK.

The band 3-based mechanism of a control of the erythrocyte shape has the major following features. Band 3 (AE1, SLC4A1) is a 90-100 $\mathrm{kDa}$ transmembrane glycoprotein which rapidly exchanges chloride $\left(\mathrm{Cl}^{-}\right)$and bicarbonate $\left(\mathrm{HCO}_{3}^{-}\right)$. It is bound to ankyrin $\mathrm{R}$ which binds in the mid region of the flexible filamentous tetrameric anionic spectrin. The latter forms a two-dimensional skeleton with band $4.1 \mathrm{R}$ and actin. Band $4.1 \mathrm{R}$ and actin form ternary complexes at the two ends of filamentous tetrameric anionic spectrin. Actin forms protofilaments binding 5-6 molecules of band $4.1 \mathrm{R}$ which is bound to the transmembrane glycoprotein $\mathrm{C}$. Band 3 also transports endogenous inorganic phosphate $\left(\mathrm{P}_{\mathrm{i}}\right)$ (its dibasic form is transported with a 
hydrogen ion $\left(\mathrm{H}^{+}\right)$) and a wide variety of other inorganic and organic anions, including bulky ones, but at a slow rate [15]. The obligatory alternative recruitment of its inward-facing (band $3_{\mathrm{i}}$ ) and outward-facing (band $3_{\mathrm{o}}$ ) conformations in exchanges of $\mathrm{Cl}^{-}$and $\mathrm{HCO}_{3}^{-}$folds and unfolds spectrin (or contracts and relaxes the skeleton), thus promoting echinocytosis and stomatocytosis, respectively. The band $3 \mathrm{o} /$ band $3_{\mathrm{i}}$ equilibrium ratio increases with the increase of the Donnan equilibrium ratio of anions $\mathrm{Cl}^{-}$and $\mathrm{HCO}_{3}{ }^{-}$and $\mathrm{H}^{+}$ $\left(\mathrm{r}=\mathrm{Cl}_{\mathrm{i}}^{-} / \mathrm{Cl}_{\mathrm{o}}^{-}=\mathrm{HCO}_{3 \mathrm{i}}^{-} / \mathrm{HCO}_{3 \mathrm{o}}^{-}=\mathrm{H}_{\mathrm{o}}^{+} / \mathrm{H}^{+}{ }_{\mathrm{i}}\right)$, which is determined by hemoglobin and the major organic phosphate intermediate 2,3-bisphophoglycerate (2,3-BPG). Substrates slowly transported by band 3, preferentially inwardly and outwardly are echinocytogenic and stomatocytogenic, respectively.

An examination of observations on the inhibition of the band 3 anion exchange by FDNB (0.15-0.3 $\mathrm{mM})$ in resealed ghosts at $37^{\circ} \mathrm{C}$ shows that this inhibition is due to a dinitrophenylation of Lys 539, one of the two lysine residues intramolecularly cross-linked by impermeant 4,4'-diisothiocyanodihydrostilbene-2,2'- disulfonic acid ( $\mathrm{H}_{2}$ DIDS) (Lys 539, Lys 851), a high affinity inhibitor of the band 3 anion exchange $[7,9,16]$. Lys 539 is not essential of the band 3 anion exchange although is nearby of the transport site [1618]. Impermeant $\mathrm{H}_{2}$ DIDS initially binds non-covalently to band 3 when its outward-facing conformation (band $3_{\mathrm{o}}$ ) is recruited or when the band $3_{\mathrm{o}} /$ band $3_{\mathrm{i}}$ ratio increases [19], which recruitment is stomatocytogenic according to the band 3-based mechanism. However, a recruitment of the band 3 inward-facing conformation subsequently occurs according to this mechanism, as indicated by an echinocytosis by impermeant covalently modifying 4,4'-diisothiocyanodihydrostilbene-2,2'- disulfonic acid (DIDS) (0.01-0.02 mM, $\left.37^{\circ} \mathrm{C}\right)[20,21]$, or non-covalently modifying 4,4'dinitrostilbene-2,2' - disulfonic acid (DNDS) $\left(2.5 \mathrm{mM}, 22^{\circ} \mathrm{C}\right)$ [21]. The degree of echinocytosis by DNDS correlates with the degree of band 3 saturation without observing a spheroechinocytosis after band 3 saturation, indicating that the echinocytosis is due to the inhibition of the band 3 anion exchange. The inference of a stomatocytosis followed by an echinocytosis by a stilbenedisulfonic acid derivative is supported by previous stopped-flow kinetics of binding of covalently modifying DIDS or non-covalently modifying 4,4'-dibenzaminostil-bene-2,2'- disulfonic acid (DBDS) to band 3 in ghosts which show that there is initially a fast phase, followed by a slower phase of its binding, which are dependent and independent of their concentrations, respectively $[22,23]$. The inhibition of the band 3 transport of $\mathrm{Cl}^{-}$by a stilbenedisulfonic acid derivative is competitive although this derivative does not fully inhibit $\mathrm{Cl}^{-}$binding to the transport site, as indicated by $\mathrm{Cl}^{-}$binding to band 3 in ghosts by chloride- 35 nuclear magnetic resonance $\left(\mathrm{Cl}^{35}\right.$ NMR) spectroscopy [23, 24]. It is attributed either to the binding of the stilbenedisulfonic acid derivative to the transport site [24] or to an allosteric site [23]. However, the following observations would support the view that the derivative binds to the transport site. Echinocytogenic stilbenedisulfonic acid derivatives DNDS and DBDS [25] are slowly transported by band 3 and substrates slowly inwardly transported by band 3 are echinocytogenic. Erythrocytes in a suspension at a low hematocrit $(0.02 \%)$ in a low ionic strength of an isotonic sucrose solution buffered by sodium phosphate, $\mathrm{pH} 5.2$ undergo a rapid morphological transformation from echinocytes to stomatocytes [26]. The presence of these echinocytocytes can be attributed to an inward transport of $\mathrm{P}_{\mathrm{i}}$ by band 3, favored by acid $\mathrm{pH}$ of the medium and an increase of the band $3_{\mathrm{o}}$ /band $3_{\mathrm{i}}$ ratio by increasing the Donnan ratio, whereas the transformation of echinocytes to stomatocytes can be attributed to the outward transport of $\mathrm{P}_{\mathrm{i}}$ transport by band 3. However, the covalent modifying stilbenedisulfonic acid derivative DIDS (0.004 $\mathrm{mM}$ ) only delays this morphological transformation.

Impermeant $\mathrm{H}_{2}$ DIDS reacts with Lys 539 at neutral $\mathrm{pH}$ without cross-linking with Lys 851, which occurs at alkaline $\mathrm{pH}$ [19]. The preferential covalent modification of Lys 539 by $\mathrm{H}_{2}$ DIDS or FDNB is attributed to its high reactivity owing to its low $\mathrm{pK}_{\mathrm{a}}$ of 8.5 which is approximately two units lower $\mathrm{pK}_{\mathrm{a}}$ of a normal lysine [7, 9]. The $\mathrm{Cl}^{35}$-NMR spectroscopy on the inhibition of the band 3 anion exchange of $\mathrm{Cl}^{-}$by FDNB in ghosts shows that this inhibition is due to an absence of the access of $\mathrm{Cl}^{-}$to the transport site [10], which could be attributed to an alteration of the threedimensional structure of the transport site by the covalent modification of Lys 539 since this lysine is close to this site. The absence of the access of $\mathrm{Cl}^{-}$to the transport site by inhibition of the band 3 anion exchange by FDNB would be stomatocytogenic according to the band 3-based mechanism of control of the erythrocyte shape since the skeleton could not be contracted by decreasing the band $3_{\mathrm{o}} /$ band $3_{\mathrm{i}}$ ratio in the absence of $\mathrm{Cl}^{-}$binding to the transport site. Consequently, it can be inferred that the stomatocytoses by the electrophilic reagents CDNB, TPCK, TLCK or 2,4dichlorophenacyl bromide are due to an inhibition of the band 3 anion exchange by a covalent modification of Lys 539 which would increase the band $3_{\mathrm{o}} /$ band $3_{\mathrm{i}}$ ratio. A stomatocytosis by the covalent modification of Lys 539 not essential of the band 3 anion exchange would raise the possibility that this lysine influences the erythrocyte shape by altering the band $3_{\mathrm{o}} /$ band $3_{\mathrm{i}}$ ratio.

The echinocytosis of erythrocytes by DNP $(1 \mathrm{mM})$ is reversed at $37^{\circ} \mathrm{C}$ by a prior treatment of erythrocytes at $4^{\circ} \mathrm{C}$ for $1 \mathrm{~h}$ by TPCK at a sub-stomatocytogenic concentration $(0.05 \mathrm{mM})$ (4 times lower) (3.7\% disc recovery/min versus $0.16 \%$ disc recovery/min of the control) in a Ringer solution buffered with N-2-hydroxyethylpiperazine- $\mathrm{N}$-ethanesulfonic acid (Hepes) supplemented with $\mathrm{MgCl}_{2}, \mathrm{P}_{\mathrm{i}}$ and glucose followed by a cell washing $[11,12]$. Its reversal by TPCK would be explained as follows. A small fraction of band 3 molecular species in each discocyte are irreversibly modified by a stomatocytogenic covalent modification of Lys 539 by TPCK at a low concentration without a visible stomatocytosis. This small modification, which by itself would relax the skeleton by increasing the band $3_{\mathrm{o}} /$ band $3_{\mathrm{i}}$ ratio, would reverse the echinocytosis by allowing an inward translocation of a certain fraction of DNP molecular species in the inner leaflet which would increase the band $3_{\mathrm{o}}$ /band $3_{\mathrm{i}}$ ratio by increasing the inner leaflet surface area, thereby further relaxing the skeleton. Alternatively, DNP molecular species inwardly translocated increases the band $3 \mathrm{o} /$ band $3_{\mathrm{i}}$ ratio by their outward transport by band 3 . This fraction may be relatively small as suggested by this observation on an erythrocyte shape transition. Sphero-echinocytes formed by 
monopalmitoylphosphatidylcholine $(0.07 \mathrm{mM})$ in a phosphate buffer saline supplemented with glucose are transformed to discocytes over a period of $7.5 \mathrm{~h}$ at $37^{\circ} \mathrm{C}$, which are transformed to stomatocytes by a selective extraction of monopalmitoylphosphatidylcholine molecular species in the outer leaflet with serum albumin [27]. This reversal transformation involves an inward translocation of a fraction of 0.13 of amphiphile molecular species in the outer leaflet which would be attributed to the increase of the band $3_{\mathrm{o}} /$ band $3_{\mathrm{i}}$ ratio by the outward transport of $\mathrm{P}_{\mathrm{i}}$ by band 3 promoted by glucose metabolism [5]. The echinocytosis by dimyristoylphosphatidylcholine, accompagnied by a vesiculation, was inhibited by TLCK at a stomatocytogenic concentration (4 mM) [13]. The explanation of this inhibition is likely to be basically the same as that of the reversal of the echinocytosis by DNP by TPCK at a substomatocytogenic concentration.

The inference that stomatocytoses by CDNB and other electrophilic reagents are due to an inhibition of the anion exchange by the covalent modification of Lys 539 of band 3 would be interest since stomatocytogenic and echinocytogenic amphiphiles are perceived to interact non-covalently with the membrane. Moreover, it can be clinically relevant since it raises the possibility that stomatocytosis in alcoholism, which can be induced in blood samples by acetaldehyde $\left(1 \mathrm{mM}, 2 \mathrm{~h}\right.$ at $\left.4^{\circ} \mathrm{C}\right)$ [28], the first metabolite produced in the hepatic ethanol metabolism, is due to a covalent modification of Lys 539 by this metabolite. Moreover, it was previously observed that an inherited deficiency of glucose-6-phosphate dehydrogenase, the enzyme catalyzing the first and rate limiting step of the pentose phosphate pathway, prevented the reversal of the echinocytosis by DNP by TPCK, indicating of an alteration of the membrane, which was also suggested by a particularly slow reversal of the echinocytosis by DNP by the activator of the pentose phosphate pathway amphiphilic methylene blue not altering the erythrocyte shape [11]. It has been previously shown that the phosphorylation of the band 3 cytoplasmic domain is increased after cysteine oxidation and increasing salt concentration in glucose-6-phosphate dehydrogenase deficiency erythrocytes [29].

\section{CONFLICT OF INTEREST}

The author confirms that this article content has no conflict of interest.

\section{ACKNOWLEDGEMENTS}

Declared none.

\section{REFERENCES}

[1] Awasthi YC, Garg HS, Dao DD, Partridge CA, Srivastava SK. Enzymatic conjugation of erythrocyte glutathione with 1-chloro2,4-dinitrobenzene: the fate of glutathione conjugate in erythrocytes and the effect of glutathione depletion on hemoglobin. Blood 1981; 58(4): 733-8.

[2] Chiu DTY, Lai KM, Xu CM, Liou SSS, Lee J, Liu TZ. Direct alteration of erythrocyte membrane properties by 1-chloro-2,4dinitrobenzene without oxidant challenge. Exp Hematol 1993; 21(1): 114-8.

[3] Sokal A, Pulaski Ł, Rcyhlyk B, Fortuniak A, Bartosz G. Is the glutathione S-conjugate pump a flippase ? Biochem Mol Biol Int 1998; 44(1): 97-105.
Zou CG, Agar NS, Jones GL. Chlorodinitrobenzene-mediated damage in the human erythrocyte leads to hemolysis. Life Sci 2002; 71(7): 735-46.

[5] Wong P. The basis of echinocytosis of the erythrocyte by glucose depletion. Cell Biochem Funct 2011; 29(8): 708-11.

[6] Haest CWM, Fischer TM, Plasa G, Deuticke B. Stabilization of erythrocyte shape by a chemical increase in membrane shear stiffness. Blood Cells 1980; 6(3): 539-53.

[7] Sato T, Ohnishi ST. Effects of sulfhydryl reagents on the antisickling activity of some membrane-interacting compounds. Biochim Biophys Acta 1983; 727(1): 196-200.

[8] Passow H, Fasold H, Gärtner EM, Legrum B, Ruffing W, Zaki L. Anion transport across the red blood cell membrane and the conformation of the protein in band 3. Ann NY Acad Sci 1980; 341: 361-83.

[9] Rudloff V, Lepke S, Passow H. Inhibition of anion transport across the red cell membrane by dinitrophenylation of a specific lysine residue at the $\mathrm{H}_{2}$ DIDS binding site of the band 3 protein. FEBS Lett 1983; 163(1): 14-21.

[10] Falke JJ, Chan SI. Molecular mechanisms of band 3 inhibitors. 3. Translocation inhibitors. Biochemistry 1986; 25(24): 7899-906.

[11] Alhanaty E, Snyder M, Sheetz MP. Glucose-6-phosphatedehydrogenase-deficient erythrocytes have an impaired shape recovery mechanism. Blood 1984; 63(5):1198-202.

[12] Alhanaty E, Sheetz MP. Cell membrane shape control-effects of chloromethyl ketone peptides. Blood 1984; 63(5): 1203-08.

[13] Bütikofer P, Brodbeck U, Ott P. Modulation of red cell vesiculation by protease inhibitors. Biochim Biophys Acta 1987; 904(2): 25967.

[14] Szatkowska B, Bukowska B, Huras B. The effect of bromfenvinphos and its impurities on human erythrocyte. Food Chem Toxicol 2011; 49(2): 502-7.

[15] Cabantchik ZI, Greger R. Chemical probes for anion transporters of mammalian cell membranes. Am J Physiol (Cell Physiol 31) 1992; 262 (4 part 1): C803-27.

[16] Okubo K, Kang D, Hamasaki N, Jennings ML. Red blood cell band 3. Lysine 539 and Lysine 851 react with the same $\mathrm{H}_{2}$ DIDS (4,4'diisothiocyanodihydrostilbene-2,2'- disulfonic acid) molecule. J Biol Chem 1994; 269(3): 1918-26.

[17] Garcia AM, Lodish HF. Lysine 539 of human band 3 is not essential for ion transport or inhibition by stilbene disulfonates. J Biol Chem 1989; 264(33): 19607-13.

[18] Wood PG, Müller H, Sovak M, Passow H. Role of Lys 558 and Lys 869 in substrate and inhibitor binding to the murine band 3 protein: a study of the effects of site-directed mutagenesis of the band 3 protein expressed in the oocytes of Xenopus laevis. J Membr Biol 1992; 127(2): 139-48.

[19] Jennings ML, Whitlock J, Shinde A. Pre-steady state transport by erythrocyte band 3 protein: uphill countertransport induced by the impermeant inhibitor $\mathrm{H}_{2}$ DIDS. Biochem Cell Biol 1998; 76(5): 807-13.

[20] Mosior M, Białas A, Wróbel A, Gomułkiewicz J. Critical cell volume and shape of bovine erythrocytes. Gen Physiol Biophys 1992; 11(5): 499-506.

[21] Schwarz S, Haest CWM, Deuticke B. Extensive electroporation abolishes experimentally induced shape transformation of erythrocytes: a consequence of phospholipids symmetrization. Biochim Biophys Acta 1999; 1421(2): 361-79.

[22] Forman SA, Verkman AS, Dix JA, Solomon AK. n-Alcohols and halothane inhibit red cell anion transport and increase band 3 conformational change rate. Biochemistry 1985; 24(18): 4859-66.

[23] Salhany JM. Mechanistic basis for site-site interactions in inhibitor and substrate binding to band 3 (AE1): evidence distinguishing allosteric from electrostatic effects. Blood Cells Mol Dis 2001; 27(5): 901-12.

[24] Falke JJ, Chan SI. Molecular mechanisms of band 3 inhibitors. 1. Transport site inhibitors. Biochemistry 1986; 25(24): 7888-94.

[25] Salhany JM, Cordes KS, Sloan RL. Band 3 (AE1, SLCA1)mediated transport of stilbenedisulfonates. I: Functional identification of the proton-activated stilbenedisulfonate influx site. Blood Cells Mol Dis 2006; 37(3): 137-48.

[26] Gimsa J, Ried Ch. Do band 3 protein conformational changes mediate shape changes of human erythrocytes? Mol Membr Biol 1995; 12(3): 247-54. 
[27] Mohandas N, Greenquist AC, Shohet SB. Bilayer balance and regulation of red cell shape changes. J Supramol Struct 1978; 9(3): 453-8.

[28] Gaines KC, Salhany JM, Duma DJ, Sorrell MF. Reaction of acetaldehyde with human erythrocyte membrane proteins. FEBS Lett 1977; 75 (1): 115-9.
[29] Bordin L, Zen F, Ion-Papa F, Barnetta M, Baggio B, Clari B. Band 3 tyr phosphorylation in normal and glucose-6-phosphate dehydrogenase-deficient human erythrocytes. Mol Membr Biol 2005; 22(5): 411-20.

Received: January 29, 2015

Revised: March 15, 2015

Accepted: May 05, 2015

(c) Pierre Wong; Licensee Bentham Open.

This is an open access article licensed under the terms of the Creative Commons Attribution Non-Commercial License (http://creativecommons.org/licenses/by-nc/3.0/) which permits unrestricted, non-commercial use, distribution and reproduction in any medium, provided the work is properly cited. 